\title{
DISCRIMINACIÓN VISUAL Y DIGITAL DE SUELOS DE BAJA CALIDAD AGRÍCOLA A PARTIR DE IMÁGENES LANDSAT*
}

\author{
Pérez González, $M^{a}$ E. y García Rodríguez, $M^{a} P$. \\ Dpto. Análisis Geográfico Regional y Geografía Física, Fac. Geografía e Historia. \\ Universidad Complutense de Madrid, Ciudad Universitaria, 28040 Madrid \\ meperez@ghis.ucm.es. Proyecto CICYT AGL 2002-02294
}

\begin{abstract}
Resumen: Este estudio se basa en el análisis de imágenes Landsat multitemporales con el objetivo de identificar suelos con baja calidad agrícola en la Comunidad Autónoma de Castilla-La Mancha. Esta categoría, dentro de los índices de calidad de suelo, incluye, entre otros, los suelos salinos y áreas con elevado riesgo de inundación. Todos ellos pueden discriminarse mediante imágenes TM y ETM, si bien es preciso el apoyo de trabajo de campo y laboratorio. Para la identificación de los suelos salinos se han analizado diferentes propiedades físicas y químicas de muestras superficiales y se han correlacionado estos datos con el Índice de Vegetación de Diferencia Normalizada (NDVI). Este Índice, escogido para fechas concretas, ha resultado de gran utilidad para detectar vegetación halófita, pese a mostrar valores digitales mucho menores a los suelos cultivados, principalmente los regadíos.
\end{abstract}

Palabras clave: calidad del suelo, salinidad, imágenes Landsat, La Mancha, España.

\begin{abstract}
This study is based on multitemporal Landsat's images in order to identify low agricultural quality soils in Castilla-La Mancha Autonomous Community. This low class, within soil quality indices, includes, among others, saline soils and floodable areas. These soils can be discriminated through TM and ETM satellite images, with field-work and laboratory support. For saline soils identification, different physical and chemical properties of surface samples have been analysed, correlating these data with Normalised Difference Vegetation Index (NDVI). This Index, used for different dates, has been quite useful in order to discriminate halophytic vegetation, despite recording lesser digital values than in cultivated land, mainly irrigated areas.
\end{abstract}

Key words: Soil quality, salinity, Landsat images, La Mancha, Spain.

\footnotetext{
* Recibido: 23-02-04. Aceptado: 4-07-04.
} 


\section{Introducción}

Estudios recientes sobre suelos destacan la necesidad de buscar un índice o indicadores que aúnen y definan las diferentes características edáficas en términos de "calidad". Se busca que la terminología resultante sea sencilla y pueda aplicarse a la gestión del territorio y sea aprovechada por un amplio abanico de profesionales: políticos, agricultores, ganaderos, forestales, urbanistas, etc. Entre los pioneros en el diseño de un índice de amplio uso se encuentra el Departamento de Agricultura de los Estados Unidos (USDA), que define la calidad de los suelos como "la capacidad de funcionar de un tipo específico de suelo. En general, es evaluada midiendo un número mínimo de datos de propiedades del suelo para estimar la capacidad del suelo de realizar funciones básicas" (USDA, 1999). Además, son numerosas las obras que tratan sobre estudios de calidad aplicados a suelos agrícolas, entre los que cabe destacar los trabajos de Doran et al.(1994); Hortensius y Welling (1996); Bouma (1997); Gilley et al. (1997); Karlen et al. (1997); Kettler, et al. (2001); Norfleet et al. (2001); Gajda, et al. (2001); Doran (2002) etc.

En la Comunidad Autónoma de Castilla- La Mancha se está investigando cuáles son los principales indicadores que enmarcan los suelos en una determinada posición dentro de una escala de calidad. Entre las diferentes categorías de calidad, los suelos salinos lógicamente se sitúan en los puestos más bajos, pues no permiten (o limitan mucho) su aprovechamiento agrícola. En dicha Comunidad, buena parte de los suelos salinos están asociados geográficamente a humedales, que se localizan principalmente en la comarca de La Mancha. Aquí se dan cita un amplio conjunto de zonas húmedas, que abarca desde áreas tan conocidas como el Parque Nacional de las Tablas de Daimiel y las lagunas de Ruidera, hasta medio centenar de lagunas que se distribuyen por las provincias de Toledo, Ciudad Real, Cuenca y Albacete. Su origen responde a la compleja interacción de factores: fluviales, kársticos, topográficos, tectónicos, distribución litológica o movimientos de aguas subterráneas. El desconocimiento del origen o fuentes de alimentación natural ha llevado en La Mancha, pero también en gran parte de humedales del resto del planeta, a su desaparición o contaminación masiva; en definitiva, a una pésima gestión del territorio. Ya Marsh et al., (1991) señalaron que la agricultura ha sido la responsable de la desecación de los terrenos pantanosos en Europa La actuación inadecuada por parte del hombre en muchos humedales ha afectado también a su entorno, especialmente si sus suelos son salinos y no resultan adecuados para la agricultura. Pasan así a convertirse, en muchos municipios, en vertederos de basuras o balsas de desagüe para las aguas residuales.

Por lo general, la prioridad en la gestión medioambiental viene determinada por la presencia, rareza o abundancia de determinadas especies vegetales y animales; mientras que otros valores de los humedales (freno de inundaciones o función des- 
contaminadora natural de numerosos compuestos de nitrógeno, fósforo, azufre, etc.) no son considerados en la planificación territorial, lo que les conduce a ser áreas marginales y, con ellos, los suelos del entorno.

\section{Objetivos}

En este trabajo se trata de conocer si los suelos salinos vinculados a humedales pueden reconocerse mediante imágenes de satélite. Esto facilitaría, al menos, la cartografía de las clases de baja calidad edáfica para amplios territorios, como es el caso de la Comunidad Autónoma de Castilla- La Mancha. Por ello, en el presente artículo se discriminan visual y digitalmente los suelos salinos, con el propósito de poder hacer una cartografía en próximos estudios.

La identificación de los suelos salinos se apoya, como no podía ser de otro modo, en la clasificación puntual de algunos suelos mediante trabajo de campo y laboratorio (Carlevaris et al., 1982; Monturiol et al., 1984; Peinado, 1994; Pérez, 1995 y Sánchez, 1997), y en el conocimiento de los factores geográficos que facilitan la acumulación de sales en los diferentes horizontes del suelo. No obstante, el análisis de las imágenes de satélite permitirá la extrapolación de casos puntuales a otros ámbitos similares. Existe una extensa bibliografía acerca de la utilidad de la teledetección en el estudio de los suelos salinos (Mougenot y Pouget, 1993; Verma et al., 1994; Sharma et al., 1994; Pulido et al., 1997; Pérez et al., 2000; Zinck, 2001; Al-Khaier, 2003; etc.) y, de estos trabajos, resultan de gran utilidad los que relacionan la vegetación, a través de diferentes indices, con los suelos salinos. A priori, el principal inconveniente en el empleo del Índice de Vegetación de Diferencia Normalizada (NDVI) es que ofrece una respuesta muy baja de la vegetación halófita, pues ésta tiene escaso porte aéreo y cobertura espacial. Por ello, cuando se comparan algunos cultivos, especialmente en regadío, con la vegetación halófita ésta suele pasar inadvertida. Sólo la selección de fechas, coincidentes con la máxima floración de las plantas halófitas y su comparación con valores de campo, puede facilitar la identificación y cartografía de los suelos salinos.

\section{Material}

Para identificar los suelos salinos se han seleccionado seis imágenes Landsat TM y ETM de diferentes meses y años, con el fin de elegir aquellas que permitan una mejor discriminación de estos suelos. Las imágenes corresponden a miniescenas flotantes TM (entre las órbitas 200/32 y 200/33) de fechas 5-11-1992, 26-8-1995, 20-21997 y escenas ETM (órbita 201/32) del 6-6-2001, 10-9-2001 y 25-6-2002. 


\section{Métodos}

Las imágenes Landsat se han georreferido a coordenadas UTM y han sido corregidas radiométrica y espectralmente mediante el programa ERDAS Imagine 8.6. Las seis escenas son analizadas visualmente, en los canales visibles e infrarrojos no térmicos, independientes y mezclándolos entre sí, para detectar las superficies ocupadas por suelos salinos. Entre las mejoras radiométricas se ha efectuado una ecualización del histograma. Entre las mejoras espectrales se han obtenido diversas composiciones con componentes principales e índices de vegetación y minetalógicos (Mulders, 1987, Cihlar et al. 1991, Metternicht y Zinck, 2003), con el fin de obtener una mejor visualización de las áreas degradadas. Para ello, a todas las imágenes se les han aplicado distintos índices (B4/B3, B4-B3/B4+B3, B3/B1, B5/B7- B5/B4-B3/B1 y B5/B7- B3/B1$\mathrm{B} 4 / \mathrm{B} 3$ ) en los que se destaca la vegetación halófita y la máxima extensión de suelos salinos. De todos ellos se ha seleccionado el Índice de Vegetación de Diferencia Normalizada (NDVI, B4-B3/B4+B3) por ser el que mejor detecta las condiciones salinas. También se ha analizado la imagen pancromática del sensor ETM ya que su mayor resolución espacial permite una mejor delimitación de algunos elementos; sin embargo, esta imagen no capta con nitidez las áreas salinas, por lo que sólo la hemos utilizado como apoyo para establecer patrones espaciales.

Con el fin de correlacionar la respuesta espectral de las imágenes con la verdadterreno se ha delimitado un área piloto entre las provincias de Toledo y Ciudad Real definida por las coordenadas geográficas $39^{\circ} 39^{\prime} \mathrm{N}-3^{\circ} 23^{\prime} \mathrm{W}$ y $39^{\circ} 22^{\prime} \mathrm{N}-3^{\circ} 4^{\prime} \mathrm{W}$ (Fig. 1). Después de identificar los suelos salinos que rodean algunos humedales, se han tomado 15 muestras de la superficie del suelo en los tres tipos de sedimentos predominantes en el sur de la laguna Larga de Villacañas, y que dan lugar a suelos con propiedades físicas y químicas muy dispares y, por tanto, a diferentes coberturas del suelo. Estas muestras se han tomado siguiendo un transecto en dirección SE desde el borde de la laguna y con una distancia entre ellas de 35-40 m, superior, por tanto, a la resolución espacial del satélite Landsat. De todas ellas se han seleccionado 4 representativas de cada tipo de material y/o vegetación y se han analizado en laboratorio, determinando los siguientes parámetros: $\mathrm{pH}$ en agua $(1: 2,5)$, conductividad eléctrica (1:5), textura (pipeta de Robinson), carbonatos (calcímetro de Bernard), materia orgánica (método de Walkley y Black) y color (tablas Munsell). Estos datos se han correlacionado (coeficiente de correlación de Pearson) con los valores del NDVI de la imagen de otoño.

Gracias a la respuesta visual y digital de las imágenes de satélite la información puntual obtenida en campo y laboratorio se extrapola a otros suelos salinos de humedales próximos y características similares: Alcázar de San Juan, Peña Hueca, El Taray y Quero. Esta extrapolación ha sido posible al tener datos analíticos de los suelos de estos humedales (Peinado, 1994; Pérez, 1995, y Sánchez, 1997) y, por tanto, tener 


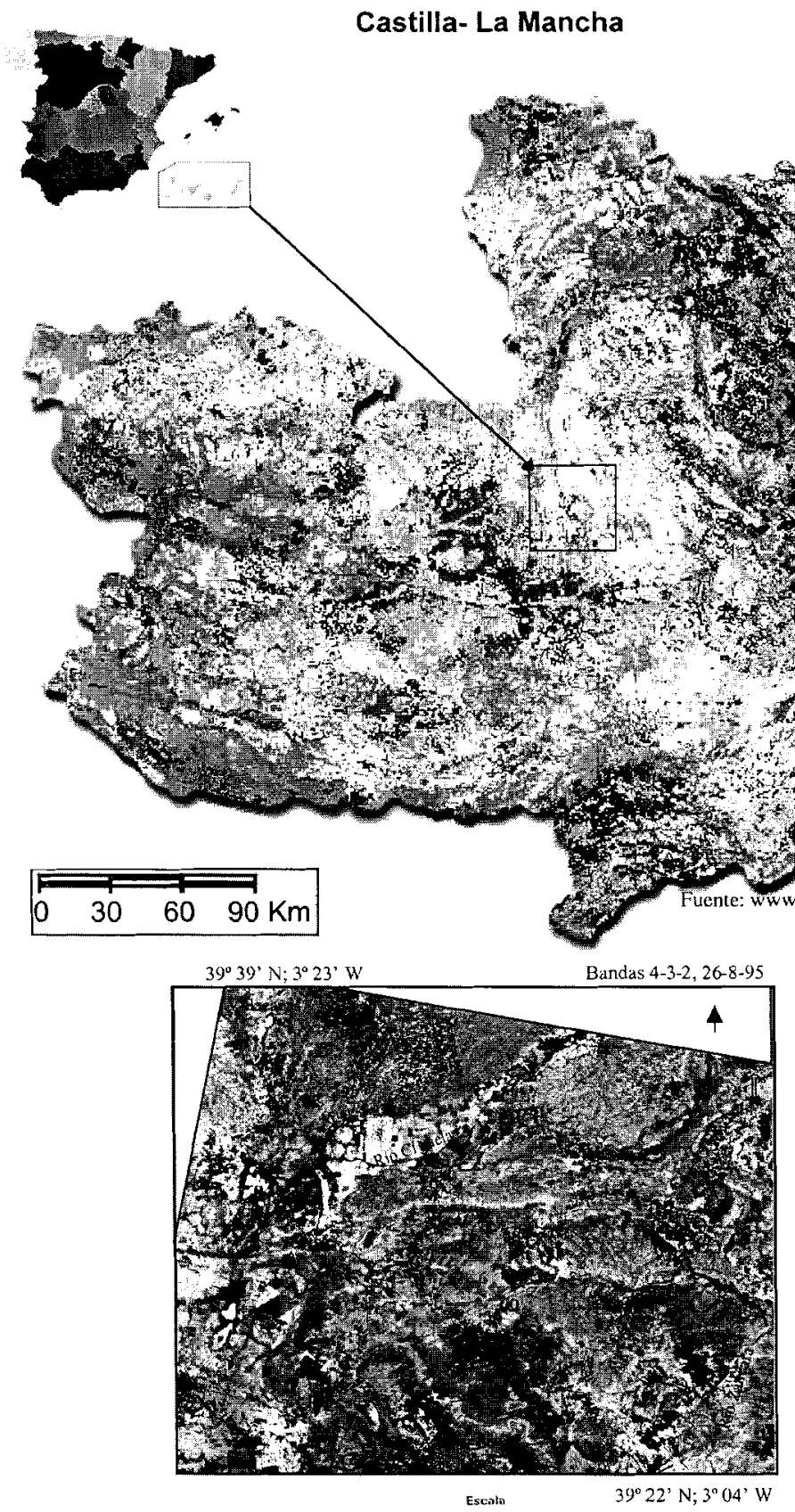

Figura 1. Localización del área de estudio en una imagen Corine Land Cover y detalle del área en una imagen Landsat TM. 
identificados y localizados algunos perfiles con propiedades sálicas. Mediante las imágenes se puede comprobar la respuesta espectral de los lugares donde aparecen los suelos salinos y tratar de delimitar su extensión. Evidentemente, la teledetección no nos permite clasificar los perfiles dentro de las distintas unidades de suelos salinos (Solonchaks o Solonetz), para lo que necesitaríamos los datos puntuales de capacidad de intercambio catiónico, identificación de horizontes, diagnóstico, etc. Pero permite visualizar las áreas en las que las sales afloran en superficie y repercuten en la vegetación.

\section{5. Área de estudio}

La comarca de La Mancha se caracteriza por un clima semiárido mediterráneo en el que las precipitaciones anuales son bajas $(300$ y $500 \mathrm{~mm}$ ) e irregulares, con variaciones espaciales sensibles que responden básicamente a pequeñas diferencias altitudinales, a la exposición y al mayor o menor alejamiento de los sistemas montañosos que enmarcan este espacio: Montes de Toledo y estribaciones occidentales del Sistema Ibérico. Así, los mínimos pluviométricos (300-350 mm) se registran en el centro de La Mancha Húmeda, en los cursos bajos de los ríos Cigüela y Záncara, y la cuantía anual va aumentando hacia el este y el oeste. Las temperaturas medias anuales oscilan entre $14,1^{\circ}$ y $15,3^{\circ} \mathrm{C}$, con mínimos en enero (de $5^{\circ}$ a $6,2^{\circ} \mathrm{C}$ ) y máximos en julio (de $25,2^{\circ}$ a $26,7^{\circ} \mathrm{C}$ ). El régimen térmico anual, de gran amplitud media (unos $20^{\circ} \mathrm{C}$ ) y media máxima (entre $32^{\circ}-34^{\circ} \mathrm{C}$ ), determina en gran parte el matiz continental del clima manchego. El clima según Thornthwaite (1948) se define como $\mathrm{DdB}_{2} \mathrm{~b}_{3}$, con una evapotranspiración anual entre $750-810 \mathrm{~mm}$, de los que el $52-54 \%$ se producen durante los meses de verano. La combinación de la intensa evapotranspiración estival y las nimias precipitaciones en estas fechas tendrá un papel destacado en el ascenso de sales en los suelos del entorno de los humedales.

Geológicamente las formaciones más antiguas presentes en este sector manchego y que sirven de base para la sedimentación de las series más modernas pertenecen al Paleozoico. Las cuarcitas ordovícicas afloran a la superficie en pequeñas alineaciones montañosas al norte (Sierra del Romeral) y al oeste del área estudiada (Cerros del Polillo, Antónamas, etc.). Estas formaciones, intensamente fracturadas, van hundiéndose progresivamente hacia el este y sudeste. Cada escalón del basamento, que determina en parte el espesor de la sedimentación mesozoica y cenozoica, tendrá una respuesta en la localización y enclave del complejo conjunto de humedales manchegos. Los sedimentos mesozoicos del Triásico afloran a modo de pequeñas manchas en torno a algunos humedales (lagunas de Villacañas, Villafranca o Quero) y con gran extensión entre las localidades de Alcázar de San Juan y Campo de Criptana. Estos materiales, ricos en sales, determinarán buena parte del desarrollo de 
los suelos salinos de La Mancha, pero para ello es necesario que vayan asociados a una topografía deprimida y a una dinámica del agua subterránea y subsuperficial favorable a la acumulación de las sales en el perfil del suelo frente al lavado y lixiviación de las mismas.

La mayor parte del territorio está ocupado por sedimentos cenozoicos de origen detrítico (gravas, arenas, arcillas y limos) y químico (calizas, margas y yesos). La incisión fluvial cuaternaria fue mínima en este sector manchego, por lo que los principales ríos que drenan el territorio muestran una vasta llanura de inundación (especialmente el río Cigüiela) y escasísimas terrazas fluviales.

Hidrológicamente, toda el área pertenece a la cuenca alta del río Guadiana, que está constituida por los ríos Cigüela y Záncara. Frente a los pequeños volúmenes de aguas superficiales este espacio destaca por ser un área de descarga de aguas subterráneas, que tienen su área fuente en los numerosos pliegues mesozoicos conquenses que constituyen las estribaciones más occidentales del Sistema Ibérico.

La intensa actividad agrícola y ganadera de La Mancha ha conducido a que la vegetación natural quede confinada a escasos y pequeños enclaves, que por diversos motivos no han podido ser cultivados: pendientes acentuadas, salinidad excesiva, escasez o pobreza del suelo, frecuencia de inundaciones, etc. Salvo algún pie de encina (Quercus rotundifolia) aislado, sin estrato arbustivo ni herbáceo alguno que recuerde a la vegetación potencial del piso mesomediterráneo, la vegetación natural queda relegada a los numerosos humedales y a la vegetación de ribera. Por ello, las especies predominantes se corresponden con saladares-salinos mediterráneos (Salicornias, Suaedas, Salsolas, Scirpus, Shoenus nigricans, Microcnemun coralloide, Juncus maritimus, Limonium $s p$., etc.) y con especies riparias basófilas (Tamarix $s p$. Cladium mariscus, Pbragmites australis, etc.) o indiferenciadas (Populus alba, Arundo donax, etc.). Trabajos más detallados sobre la vegetación higro-halófita de cada una de las lagunas manchegas han sido realizados por Cirujano (1980) y Cirujano et al.(1992).

En la comarca de La Mancha las mayores extensiones de suelos corresponden (Monturiol et al., 1984 y Carlevaris et al., 1992) a cambisoles y regosoles asociados a calcisoles y luvisoles. En las llanuras de inundación de los diferentes ríos aparecen fluvisoles asociados a gleysoles y suelos salinos; concretamente, en la llanura de inundación del Cigüela, en la provincia de Ciudad Real, aparecen solonchaks asociados a kastanozems, fluvisoles, regosoles y calcisoles. Estos suelos rodean también las lagunas de Villafranca. Pero alrededor de todos ellos dominan los cambisoles. En el área de Pedro Muñoz hay una mancha extensa de calcisoles asociados a cambisoles, regosoles y luvisoles todos ellos cálcicos. En el río Záncara hay una extensa mancha de arenosoles. En el resto del área se localizan cambisoles cálcicos y en el sur luvisoles crómicos En general son suelos ricos en carbonato cálcico, con pH altos que se cla- 
sifican en unidades calcáricas y/o eútricas. Según USDA, estos suelos se pueden clasificar como entisoles, inceptisoles y alfisoles, con régimen de humedad xérico.

La mayor parte de la superficie manchega analizada tiene como uso dominante la agricultura, con un claro predominio de los cultivos leñosos (viñedo y olivar) y cereales de grano (cebada y trigo fundamentalmente) respecto a otros cultivos agrícolas (hortalizas, forrajeras, leguminosas, etc.). En este sector manchego son pocas y pequeñas las parcelas con regadío - dedicadas a remolacha azucarera, patatas tardías, cebollas, etc.-, debido seguramente a la mala calidad del agua subterránea. Esto contrasta con áreas próximas a las Tablas de Daimiel, donde los cultivos en regadío son dominantes. Los cultivos de regadío se identifican claramente en las imágenes Landsat utilizando el infrarrojo próximo (banda 4), especialmente resaltable en las imágenes de verano.

\section{Resultados y discusión}

En la comarca de La Mancha los suelos vinculados a humedales salinos suelen limitarse a su entorno inmediato distribuyéndose de forma concéntrica en torno a los vasos lagunares. La mayor cantidad de sales en los perfiles superficiales viene determinada por los sedimentos superficiales e infrayacentes y por los movimientos de aguas subsuperficiales y subterráneas en terrenos deprimidos. La distribución y extensión de los suelos salinos en las lagunas manchegas queda representada por el transecto realizado en la laguna de Villacañas, desde la lámina de agua hasta los suelos cultivados; en él se observa la siguiente distribución espacial:

- Suelos salinos en los bordes de la laguna, saturados en agua, con alto contenido en materia orgánica y color grisáceo que constituyen sapropel.

- Suelos salinos menos saturados en agua que sustentan una densa vegetación higro-halófita. La proporción y densidad de plantas halófitas disminuye considerablemente al alejarse de los vasos lagunares. En sus proximidades dominan quenopodiáceas (Salicornia, Microcnemum, Suaeda, Salsola, etc.) y cyperáceas (Schoenus nigrican, Scirpus, etc.); conforme disminuye la saturación de agua en el suelo y la concentración de sales éstas se combinan con plumbagináceas (Limonium) y gramíneas (Lygeum, Elymus, etc.).

- Suelos pobres en sales (o sin ellas) dedicados a cultivos de cereales con escasa rentabilidad. Algunas parcelas más alejadas de la laguna se aprovechan para cultivos de regadío. 
Se han obtenido los principales parámetros físicos y químicos de la superficie del suelo en un transecto de $150 \mathrm{~m}$ escogiendo las cuatro muestras más representativas de los diferentes materiales geológicos y cubiertas del suelo. Estos datos quedan reflejados en la tabla 1 y en la figura 2.

Tabla 1. Parámentros físico-químicos de los suelos del sur de la laguna de Villacañas (Toledo).

\begin{tabular}{|cccccccccccccc|}
\hline Muestras & $\begin{array}{c}\text { Material } \\
\text { original }\end{array}$ & $\begin{array}{c}\text { Ocupación } \\
\text { suelo }\end{array}$ & $\begin{array}{c}\text { Color } \\
\text { Seco }\end{array}$ & $\begin{array}{c}\text { Color } \\
\text { Húmedo }\end{array}$ & $\begin{array}{c}\text { Arena } \\
\text { Gruesa } \%\end{array}$ & $\begin{array}{c}\text { Arena } \\
\text { Fina } \%\end{array}$ & $\begin{array}{c}\text { Limo } \\
\%\end{array}$ & $\begin{array}{c}\text { Arcilla } \\
\%\end{array}$ & pH & $\begin{array}{c}\text { C.E. } \\
(\mathrm{dS} / \mathrm{m})\end{array}$ & $\begin{array}{c}\text { M.O } \\
\%\end{array}$ & $\begin{array}{c}\mathrm{CO}_{3} \mathrm{Ca} \\
\%\end{array}$ \\
\hline 2 & Sapropel & $\begin{array}{c}\text { Algas } \\
\text { Sapropel }\end{array}$ & $\begin{array}{c}2,5 \mathrm{Y} \\
6 / 2\end{array}$ & $\begin{array}{c}2,5 \mathrm{Y} \\
4 / 2\end{array}$ & 3,0 & 74,1 & 11,5 & 11,4 & 9,1 & 7,48 & 2,96 & 15,2 \\
\hline 3 & $\begin{array}{c}\text { Sedimentos } \\
\text { triásicos }\end{array}$ & $\begin{array}{c}\text { Veg. } \\
\text { halófita }\end{array}$ & $\begin{array}{c}5 \mathrm{YR} \\
4 / 4\end{array}$ & $\begin{array}{c}5 \mathrm{YYR} \\
3 / 3\end{array}$ & 3,1 & 33,7 & 52,0 & 11,2 & 9,4 & 10,03 & 2,61 & 8,5 \\
\hline 4 & $\begin{array}{c}\text { Sedimentos } \\
\text { terciarios }\end{array}$ & Cultivos & $\begin{array}{c}2,5 \mathrm{YR} \\
4 / 8\end{array}$ & $\begin{array}{c}2,5 \mathrm{YR} \\
3 / 6\end{array}$ & 2,7 & 28,7 & 60,0 & 8,6 & 9,0 & 3,35 & 2,07 & 5,5 \\
\hline & $\begin{array}{c}\text { Sedimentos } \\
\text { terciarios }\end{array}$ & Cultivos & $\begin{array}{c}5 \mathrm{YR} \\
5 / 4\end{array}$ & $\begin{array}{c}5 \mathrm{YR} \\
4 / 4\end{array}$ & 7,0 & 40,6 & 20,4 & 32,0 & 8,9 & 0,85 & 1,65 & 8,8 \\
\hline
\end{tabular}

El color de los suelos es muy contrastado a lo largo de transecto "laguna-cultivos". La primera muestra tiene colores grises, con un marcado cambio a tonos rojos oscuros en los materiales triásicos (muestra 2). Las muestras 3 y 4 tomadas en los suelos dedicados a cultivos son pardo rojizas y rojo amarillentas, pero sensiblemente más claras que las correspondientes a sedimentos mesozoicos. La textura, aun siendo arenosa en la primera muestra, es siempre muy fina, ya que el tamaño de las arenas es, en la mayoría, inferior a $0,08 \mathrm{~mm}$.

Los datos de pH y conductividad eléctrica están muy relacionados con las coberturas del suelo. El sapropel, pese a estar embebido en agua, mantiene valores de C.E. muy elevados, característicos de suelos salinos. Las muestras del material triásico con pH y C.E. muy altos, sólo pueden sustentar plantas halófitas, ya que su alta salinidad impide su utilización agrícola. Por el contrario, al alejarnos de la laguna y entrar en los materiales terciarios, los suelos ya no se pueden considerar salinos (puesto que no tienen propiedades sálicas, siguiendo los criterios de FAO, 1999) y son utilizados para cereales de invierno.

La presencia de algas en el sapropel y la densa cubierta de plantas halófitas hacen que las primeras muestras tengan un contenido relativamente elevado en materia orgánica, disminuyendo ésta conforme los suelos pasan a ser cultivados y, por tanto, recolectada la masa vegetal a principios de verano.

La variabilidad que se observa en los parámetros físico-químicos y en la vegetación, al hacer un corte transversal desde el borde de la laguna hasta los suelos agrícolas, 

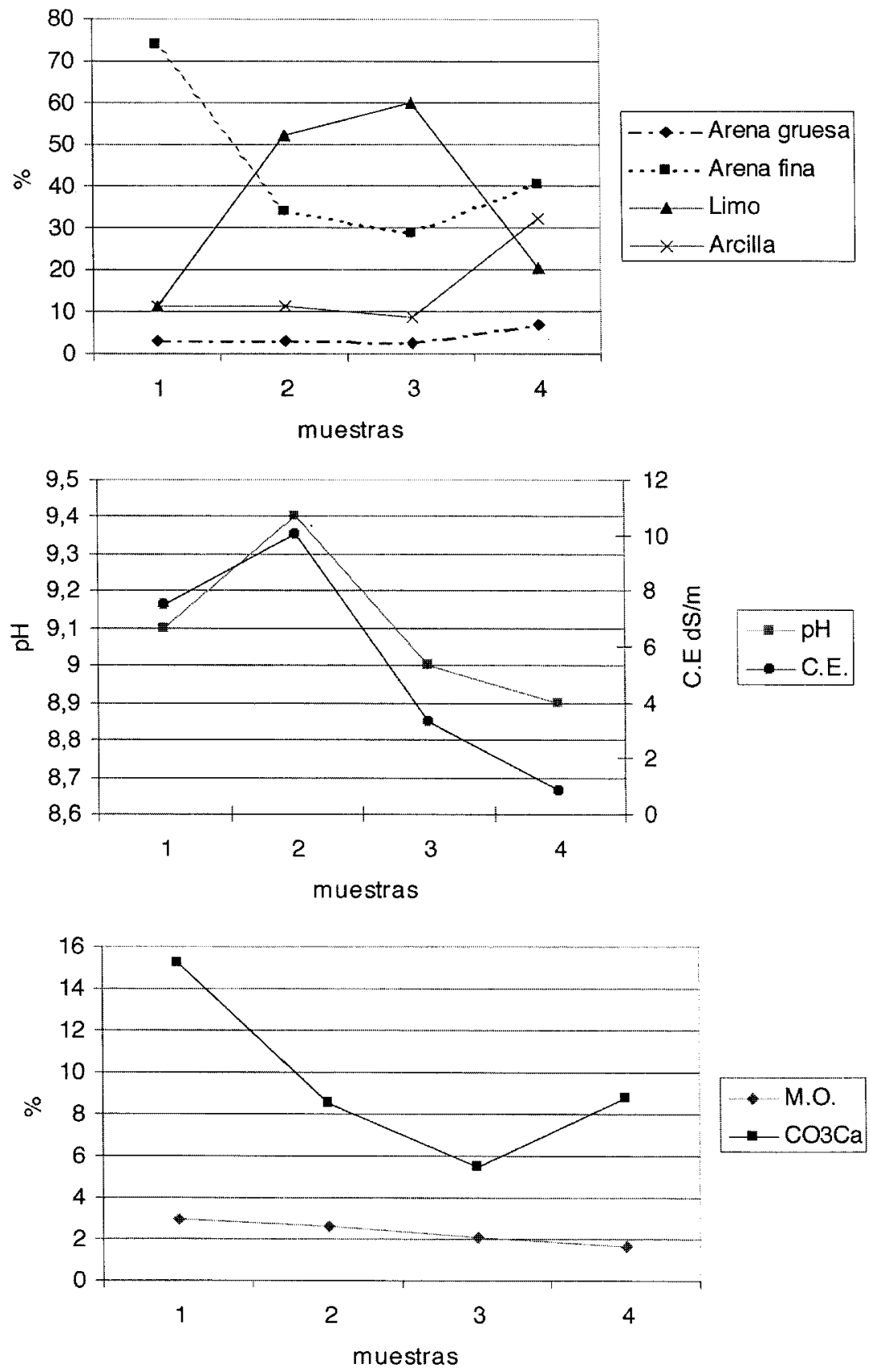

Figura 2. Datos analíticos en el transecto al Sur de la Laguna Larga de Villacañas. 
puede detectarse también mediante las imágenes Landsat TM y ETM. No obstante, la escasa superficie ocupada por los suelos salinos en este sector manchego obliga a realizar estudios de detalle en cada uno de los humedales, ya que la resolución espacial del satélite Landsat $(30 \mathrm{~m})$ no permite por si sólo la identificación de dichos suelos.

El análisis visual de diferentes combinaciones de bandas refleja tonos muy claros en los suelos salinos, yesos, calizas, eflorescencias salinas y arenas (Figura 1). Por tanto, para poder discriminar estos suelos del resto de materiales es necesario realizar mejoras espectrales y trabajo de campo. De los diferentes análisis se han seleccionado aquellos que mejor combinan la respuesta espectral de los suelos y la vegetación. Las especies halófitas, con escaso recubrimiento espacial y poca altura, pueden diferenciarse espectralmente mediante el índice de NDVI. Para discriminarlas se ha comprobado que, de todas las fechas estudiadas, la mejor es noviembre. Los valores correspondientes al otoño, época de floración de las salicornias, suaedas, etc., ascienden ligeramente sobre los de su entorno, por lo que esta vegetación halófita se discrimina visual y digitalmente. La imagen del NDVI (Figura 3) permite reconocer una orla blanca alrededor de los humedales salinos, aunque sin ocupar el área adyacente a la lámina de agua, formada por sapropel que, con mayor contenido en humedad, ofrece tonos grises.

En la figura 4 se han representado los valores del NDVI en cuatro humedales, en fechas contrastadas, tomando muestras desde el interior de las lagunas, hasta los suelos cultivados del entorno; en dos de ellos, laguna Larga de Villacañas y laguna del Camino en Alcázar de San Juan, también se recoge el valor en el agua contaminada. En las diferentes fechas, los valores más altos de NDVI corresponden, lógicamente, a las parcelas de regadío. Excluyendo este uso, el NDVI más elevado es el correspondiente a la vegetación halófita, pero sólo en los meses de otoñoinvierno, debido a la fenología de estas especies. Por tanto, aun con valores bajos, los suelos salinos pueden discriminarse digitalmente en estas estaciones. El sapropel, pese a tener contenidos relativamente altos en materia orgánica, no ofrece respuesta positiva en el NDVI. La eutrofización de las dos lagunas contaminadas se pone de manifiesto en los valores más altos del NDVI, frente a las aguas sin contaminar, especialmente en verano. El área de cultivos en secano al estar en un sector marginal, sin cultivarse todos los años y en otoño/invierno estar desprovista de vegetación, muestra valores de NDVI muy bajos, tanto en la escena de noviembre como en febrero.

En la tabla 2 se calcula la relación entre los datos analíticos de las muestras de los suelos y los valores de NDVI en el transecto de la laguna de Villacañas. Existe una alta correlación entre los valores de NDVI y los de conductividad eléctrica y pH. Cabe destacar que en otoño el único sector del entorno lagunar con vegetación se desarrolla sobre suelos salinos, por lo que el coeficiente de Pearson entre NDVI y C.E. está próximo a la unidad. La relación entre estos dos parámetros es positiva y muy 

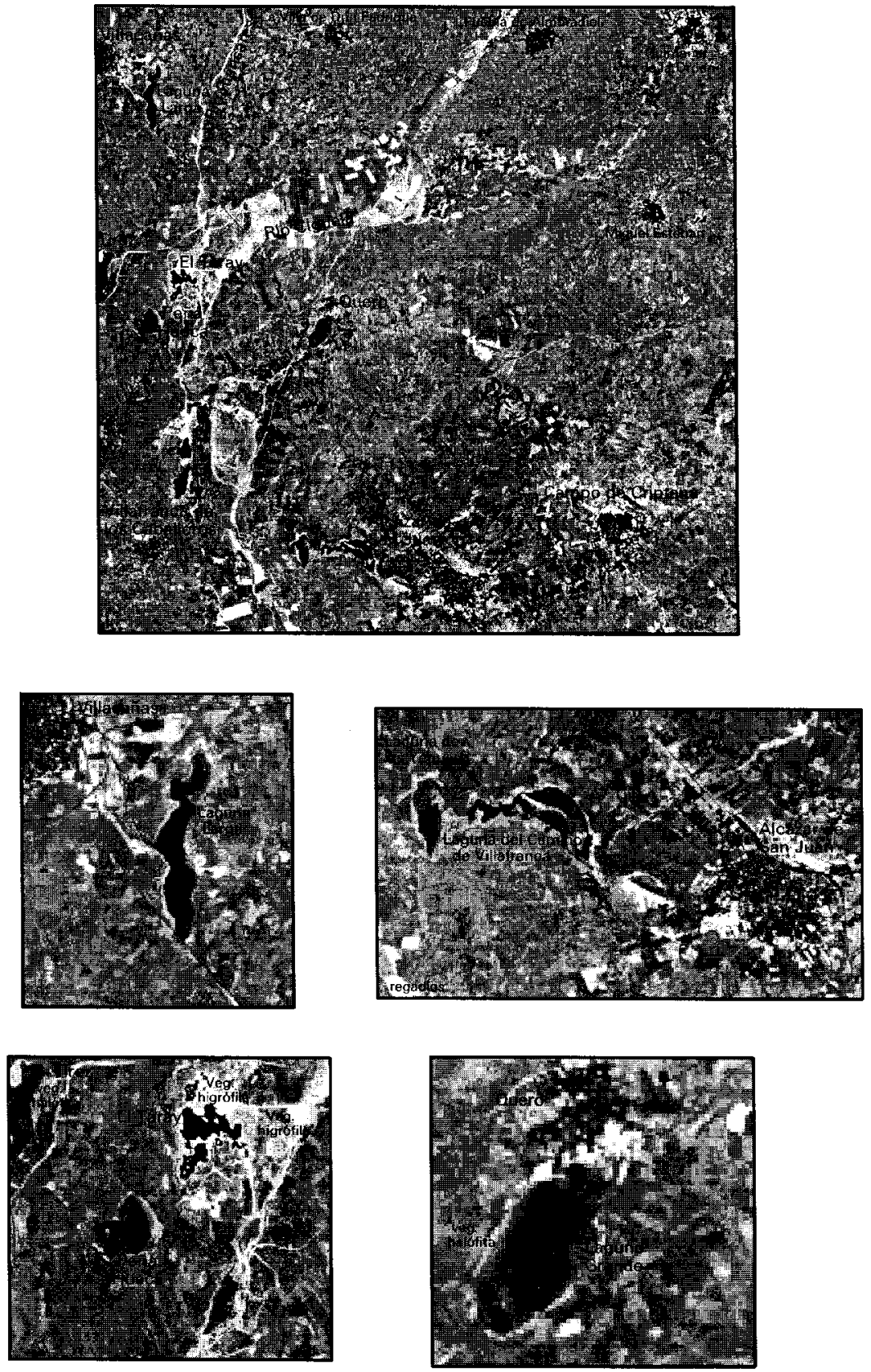

Figura 3. Indice de Vegetación Normalizado de la imagen de otoño.

Detalle de la orla de vegetación halófica (tonos blancos) en los bordes de las lagunas. 

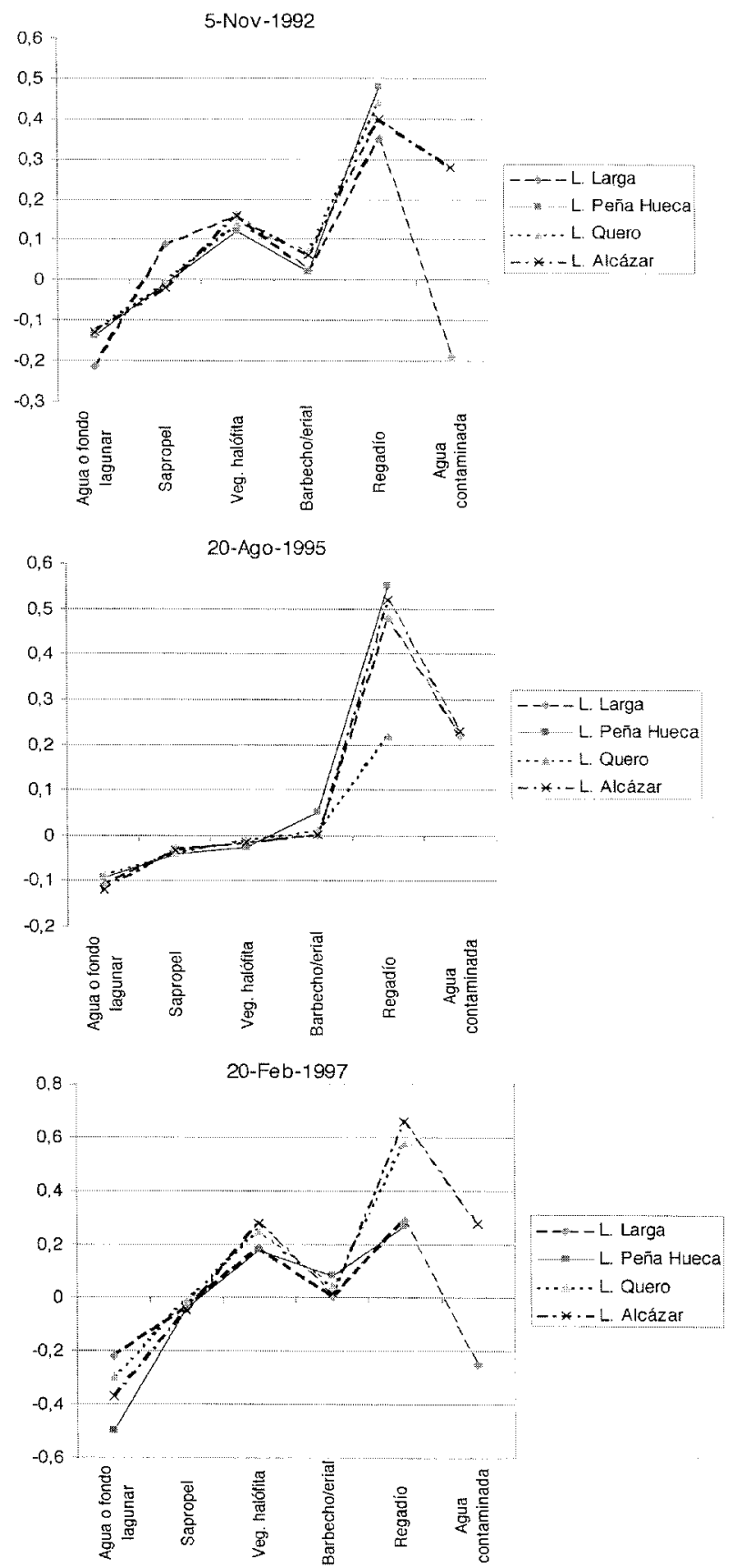

Figura 4. Valores de NDVI en los suelos de humedales manchegos. 
alta en otoño, por encontrarse las parcelas de cultivo en tareas de laboreo. De seleccionar otra fecha, la menor respuesta de las especies halófitas frente a los cultivos amortiguaría la relación entre ambos parámetros. Estos datos se pueden extrapolar a otras lagunas, delimitando, a partir de las imágenes TM, la extensión de la vegetación halófita y por tanto los suelos salinos.

Tabla 2. Coeficiente de correlación de Pearson entre datos analíticos y NDVI del 5-11-92

\begin{tabular}{|c|c|c|c|c|c|c|c|c|c|}
\hline Arena $\mathrm{G}$. & $\begin{array}{c}\text { Arena } G \\
1\end{array}$ & Arena $\mathrm{F}$. & Limo & Arcilla & $\mathrm{pH}$ & C.E. & M.O. & $\mathrm{CO} 3 \mathrm{Ca}$ & NDVI \\
\hline Arena F. & $-0,08$ & 1 & & & & & & & \\
\hline Limo & $-0,47$ & $-0,84$ & 1 & & & & & & \\
\hline Arcilla & 0,99 & $-0,04$ & $-0,51$ & 1 & & & & & \\
\hline p.H. & $-0,56$ & $-0,06$ & 0,36 & $-0,55$ & 1 & & & & \\
\hline C.E. & $-0,68$ & 0,24 & 0,15 & $-0,67$ & 0,94 & 1 & & & \\
\hline M.O. & $-0,73$ & 0,63 & $-0,16$ & $-0,70$ & 0,65 & 0,87 & 1 & & \\
\hline $\mathrm{CO} 3 \mathrm{Ca}$ & -0.07 & 0,98 & $-0,83$ & $-0,02$ & 0,09 & 0,36 & 0,68 & 1 & \\
\hline NDVI & $-0,55$ & 0,13 & 0,17 & $-0,53$ & 0,98 & 0,98 & 0,77 & 0,29 & 1 \\
\hline
\end{tabular}

\section{Conclusiones}

Aunque las imágenes de verano ofrecen la máxima distribución de las eflorescencias salinas, éstas no pueden asociarse siempre a suelos salinos, pues en ocasiones los suelos ricos en yesos, muy secos, ofrecen respuestas visuales y digitales similares a las sales. Por tanto, para delimitar los suelos salinos es necesario incluir otros elementos como el tipo de vegetación y los movimientos de agua en el suelo.

La vegetación halófita, indicadora de los suelos salinos, se discrimina mejor en los canales rojo e infrarrojo próximos y, por tanto, en los índices de vegetación que se obtienen de la relación entre estas bandas. Para delimitar las áreas ocupadas por comunidades halófitas en estas lagunas las fechas idóneas corresponden a otoño e invierno. La mayor actividad clorofílica en estos meses queda reflejada en los índices de vegetación, aunque la masa vegetal ocupe poca superficie.

Los suelos y sedimentos salinos siempre ofrecen alta reflectividad en las bandas visibles. Por el contrario en los infrarrojos próximos y medios, si los materiales tienen mucha humedad (por encima de la capacidad de campo), la absorción del agua conduce a valores digitales muy bajos, por lo que las sales quedan enmascaradas. Son, pues, los canales visibles los que ofrecen una mayor discriminación visual de los suelos afectados por salinización. 
Consideramos que el uso de la teledetección con imágenes de satélite de alta resolución espacial y/o espectral es muy útil para estudiar los suelos salinos y los factores que influyen en los movimientos de las sales. La posibilidad de hacer un seguimiento multitemporal, en diferentes años y estaciones, con importantes oscilaciones meteorológicas e hidrológicas, permitirá un mayor conocimiento de la repercusión de estos factores en el desarrollo de los suelos salinos, así como de las variaciones en la extensión de las áreas afectadas por salinización. Estas conclusiones se podrán extrapolar a sensores hiperespectrales, cada vez más utilizados en los estudios del medio físico.

\section{Bibliografía}

Al-Khaier, F. (2003): Soil salinity detection using satellite remote sensing. Thesis for the degree of Master of Science. ITC, Enschede, $70 \mathrm{pp}$.

Bouma, J. (1997): Soil Environmental Quality: An European Perspective. J. Environ. Qual., 26: p. 26-31.

Carlevaris, J.J., Horra de la, J.L. y Rodríguez, J. (1992): La fertilidad de los principales suelos agrícolas de la zona oriental de la provincia de Ciudad Real. La Mancba y Campo de Montiel. CSIC, Madrid y Consejería de Agricultura de Castilla La Mancha.

Cihlar, J., St. Laurent, L. and Dyer, J.A. (1991): Relation between the normalized difference vegetation index and ecological variables. Remote Sensing environment 35; p. 279-298.

Cirujano, S. (1980): Las lagunas salobres toledanas. Temas Toledanos, 5: p. 11-27. Instituto Provincial de Investigaciones y Estudios Toledanos, Toledo.

Cirujano, S., Velayos, M., Castilla, F. y Gil, M. (1992): Criterios botánicos para la valora- ción de las lagunas y bumedales españoles. (Peninsula Ibérica e Islas Baleares). ICONA, Madrid.

Doran, J.W., Bezdicek, D.F., Coleman, D.C. and Stewart, B.A. (1994): Defining Soil Quality for a Sustainable Environment. Soil Sci. Soc. Amer. Spec. Publ. nº. 35, p. 3-21, Madison, WI.

Doran, J.W. (2002): Soil health and global sustainability: Translating science into practice. Agriculture, Ecosystems, and Environment 88 (2), p. 119-127.

F.A.O. (1999): Guideline for soil profile description. FAO. Roma.

Gajda, A.M., Doran, J.W., Wienhold, B.J., Kettler, T.A., Pikul, J.L. and Cambardella, C.A. (2001): Soil Quality evaluations of alternative and conventional management systems in the Great Plains, In R. Lal, J.F. Kimble, and R.F. Follett and B.A. Stewart (eds.). Assessment Methods for Soil Carbon. CRC Press, Boca Raton, FL, p. 381-400.

Gilley, J.E., Doran, J.W., Karlen, D.L. and Kasper, T.C. (1997): Runoff, erosion, and soil quality characteristics of a former 
Conservation Reserve Program site. J. Soil Water Conservation, 52, p. 189-193.

Hortensius, D. and Welling, R. (1996): International Standardization of Soil Quality Measurements. Commun. Soil Sci. Plant Anal., 27, p. 387-402.

Karlen, D.L., Mausbach, M.J., Doran, J.W., Cline, R.G., Harris, R.F. and Schuman, G.E. (1997): Soil Quality: A Concept, Definition, and Framework for Evaluation, Soil Sci. Soc. Am.J., 61, p. 4-10.

Kettler, T.A., Doran, J.W. and Gilbert, T.L. (2001): A simplified method for soil particle size determination to accompany soil quality analyses. Soil Science Soc. Am. J. 65, p. 849-852.

Marsh, J., Green, B., Kearney, B., Mahe, L., Tangermann, S. and Tarditi, S. (1991): The Changing Role of the Common Agricultural Policy. The future of Farming in Europe. Belhaven press, London, 164 pp.

Monturiol Rodríguez, F. et al. (1984): Estudio Agrobiológico de la provincia de Toledo. Ins. Edaf. Veg. e Inst. Prov. Invest. Estudios Toledanos. Toledo, $378 \mathrm{pp}$.

Metternicht, G, and Zinck, J.A. (2003): Remote sensing of soil salinity: potentials and constraints. Remote Sensing of Environment, vol 85, p. 1-20.

Mougenot, B. and Pouget, M. (1993): Remote sensing of salt-affected soil. Remote Sensing Revieus, vol. 7, p. 241-259.

Mulders, M. (1987): Remote Sensing in Soil science. Elsevier. Amsterdam. The Netherlands. 379 pp.

Norfleet, L., Doran, J.W., Seybold, C., Sucik, M., Rosales, M. and Saunders, J. (2001):
Soil quality test kit guide and interpretive manual. USDA-ARS \& NRCS, Soil Quality Institute, Ames, IA.

Peinado Martín Montalvo, M. (1994): Funcionamiento y variabilidad de los geosistemas de los bumedales manchegos. Tesis doctoral, Dpto. A.G.R. y Geografía Física, Universidad Complutense de Madrid, 296 pp. con mapas y anexos.

Pérez González, Mª. (1995): Humedales de la confluencia de los ríos Riánsares y Cigüela: estudio de ciertas funciones relevantes en Geografia Física. Tesis doctoral, Dpto. A.G.R. y Geografía Física, U.C.M., 271 pp. y 3 mapas.

Pérez González, $M^{a}$ E., Sánchez Pérez de Evora, A., García Rodríguez, $\mathrm{M}^{\mathrm{a}} \mathrm{P}$. and Sanz Donaire, J.J. (2000): Análisis mediante imágenes de satélite de la salinización en la laguna Larga de Villacañas. En Lecturas Geográficas, vol. II, p. 1655-1665.

Pulido, M.L., Robles, B., Wiegand, C.L. y López, J.L. (1997): Aplicación de imágenes de satélite para identificar la salinidad del suelo y las áreas con mal drenaje. Memorias del VII Congreso Nacional de irrigación, Hermosillo, Sonora, México.

Sánchez Pérez de Evora, A. (1997): Humedales Manchegos: factores ambientales y su repercusión en los suelos. Tesis doctoral, Dpto. A.G.R. y Geografia Física, U.C.M., $405 \mathrm{pp}$.

Sharma, R.K., Sundara Sarma, K.S. y Das, D.K. (1994): Corp discriminational in salt affected soils by satellite remote sensing. GIS Development: p. 1-3.

Thornthwaite, C.W. (1948): An Approach toward a rational classification of cli- 
mate. Geographical Review 38, p. 5594.

U.S.D.A. (1999): Guía para la Evaluación de la calidad y salud del suelo. Dpto. de Agricultura. EEUU.

Verma, K.S., Saxena, R.K., Barthwal, A.K. y Deshmukh, S.N. (1994): Remote sensing technique for mapping salt affected soils, International Journal of Remote Sensing, 15 (9): p. 1901-1914.

Zinck, J.A. (2001): Monitoring salinity from remote sensing data. Proceedings of $1^{\text {st }}$ Workshop of the EARSeL Special Interest Group on Remote Sensing for the Developing Countries, p. 359-368. Belgium, Ghent University: 